\title{
Changes in Central Macular Thickness after Uncomplicated Phacoemulsification Surgery in Diabetic and Non-Diabetic Patients
}

\author{
Sezen Akkaya, Yelda Ozkurt \\ Health Sciences University Fatih Sultan Mehmet Training and Research Hospital, Istanbul, Turkey
}

\begin{abstract}
Objectives: The aim of this study was to assess changes in central macular thickness following uncomplicated phacoemulsification surgery in diabetic patients with and without retinopathy and in a control group.

Methods: The records of 43 eyes of patients with mild non-proliferative diabetic retinopathy (NPDR), 43 eyes of diabetic patients without diabetic retinopathy (no-DR), and 43 eyes of a control group that also underwent phacoemulsification surgery were prospectively reviewed. Foveal thickness was measured using optical coherence tomography preoperatively and at I week and I, 3, 6, and I 2 months postoperatively.

Results: No clinically significant differences in foveal thickness were observed preoperatively between groups. Foveal thickness had increased in the NPDR group at I week and I and 3 months after surgery, in the no-DR group at I week and I month, and in the control group at I week after surgery. Foveal thickness decreased gradually in the NPDR group after 3 months. When comparing the groups, foveal thickness was significantly greater in the NPDR group than in the noDR group and the control group at postoperative months I and 3; however, at month 6, the differences had decreased, and there were no clinically significant differences between groups.

Conclusion: Foveal thickness increased until 3 months after cataract surgery and decreased gradually thereafter in NPDR patients. Foveal thickness had also increased during the first month in the no-DR group. Foveal thickness increased only in the first week in the control group. These changes were more prominent in eyes with NPDR than in eyes with no-DR and those of the control group.
\end{abstract}

Keywords: Diabetic retinopathy, macular thickness, uncomplicated phacoemulsification surgery.

\section{Introduction}

Cataract is a common cause of decreased vision worldwide, and the treatment for cataracts is surgical removal (I). Cataracts occur more often in patients with diabetes than in those without diabetes. The worldwide prevalence of diabetes is on the rise; thus increasing the importance of the relationship between diabetes and cataracts (2). Cystoid macular edema (CME) is one of the potential complications following uncomplicated cataract surgery in patients that can cause unwanted visual outcomes (3).
Some processes may underlie pathogenic mechanisms of macular thickening, such as postoperative inflammation caused by surgically damaged tissue, the breakdown of the blood-retinal and blood-aqueous barriers, and the release of prostaglandins and vascular endothelial growth factor (VEGF) $(3,4)$.

Cataract surgery initiates an inflammatory process in the eye. The risk of macular thickening after uncomplicated phaco surgery may increase in the presence of ocular or systemic inflammatory diseases like uveitis or diabetes (5).

Address for correspondence: Sezen Akkaya, MD. Health Sciences University Fatih Sultan Mehmet Training and

Research Hospital, Istanbul, Turkey

Phone: +90 2165783000 E-mail: drsezenakkaya@gmail.com

Submitted Date: November 29, 2017 Accepted Date: March 01, 2018 Available Online Date: April 04, 2018

${ }^{\circ}$ Copyright 2018 by Beyoglu Eye Training and Research Hospital - Available online at www.beyoglueye.com 
Primarily, the status of macular thickness before the cataract surgery determines the visual outcome after surgery (6-8). Previous studies have described many diabetic patients who developed severe maculopathy, progression of retinopathy, and/or neovascular glaucoma following cataract surgery $(9,10)$. Progression of diabetic retinopathy (DR) has been demonstrated in approximately $10 \%$ to $30 \%$ of patients after uncomplicated cataract surgery $(\mathrm{II}, \mathrm{I} 2)$. Some surgeons think that the progression of DR after cataract surgery is due to the natural course of the condition, and that the progression is independent of the surgery $(5,12-14)$. According to previous studies, the most significant predictive factor for progression of DR is the status of DR before the cataract surgery $(15,16)$.

Two mechanisms may lead to macular edema after surgery. One is Irvine-Gass syndrome (transient pseudophakic edema), which usually resolves spontaneously, and the other is actual progression of diabetic maculopathy (17-19). A study reported by Kim et al. (20) revealed a short-term increase in macular thickness after cataract surgery in diabetic patients.

The purpose of this study was to demonstrate changes in macular edema that occurred after uncomplicated phacoemulsification surgery in eyes with and without DR in diabetic patients and in a control group. The foveal thickness was periodically measured using optical coherence tomography (OCT) to quantitatively compare the degree of macular edema before and after surgery. If there was a difference in foveal thickness between the measurements taken before and after surgery of $100 \mu \mathrm{m}$ or greater, the patient was treated with intravitreal anti-VEGF or micropulse laser.

\section{Methods}

All diabetic patients scheduled for phacoemulsification surgery and intraocular lens (IOL) implantation between May 2013 and July 2015 were consecutively screened for inclusion in this study. No statistically significant differences were observed between the 3 working groups with respect to average age, gender distribution, cataract grade, or mean phaco time and phaco power. The exclusion criteria were the presence of additional underlying disease other than diabetes and cataract that could affect macular thickness (e.g., uveitis, glaucoma, or epiretinal membrane), uncontrolled blood sugar level (glycated hemoglobin $>6 \%$ ), proliferative DR or preexisting macular edema, incomplete or missing baseline or follow-up data, no aggregate results, unrelated outcome measurements, and any operative complication.

Screening was continued until 43 eyes with DR, 43 eyes without DR, and 43 control eyes could be included in this study. At the time of cataract surgery, all of the patients underwent implantation of a hydrophobic acrylic IOL per- formed by 2 surgeons. The study protocol was approved by the hospital's institutional review board, and informed consent was obtained from each patient.

All of the surgeries were performed using the same technique. No significant differences were found between the 3 groups in the grade of the nucleus, ultrasound time, or ultrasound power emitted. Following a side port incision, a 3.0-mm superior incision was performed, and the continuous curvilinear capsulorhexis technique was used. Hydrodissection with balanced salt solution and cataract extraction using the bimanual "divide-and-conquer" endocapsular phacoemulsification technique was performed. Sodium hyaluronate $1.4 \%$ was injected into the capsular bag. A foldable intraocular lens was implanted (Eyecryl Plus, Biotech Vision Care Pvt. Ltd., Ahmedabad, India) using an injector. After insertion, the viscoelastic material was thoroughly evacuated. All surgeries included in the analysis were uneventful and the IOLs were implanted accurately within the capsular bag. All patients used the same steroid and antibiotic $4 x \mathrm{x}$ per day for I month after the surgery. We did not use a non-steroid anti-inflammatory drug in any patient to avoid any potential effect on the macular thickness.

The central retinal (foveal) thickness of all patients was measured with OCT (RS-3000 Advance; Nidek Co. Ltd., Gamagori, Japan) a day before surgery and I week and I, 3, 6 , and 12 months after surgery.

A fundus examination with full pupil dilation was performed before surgery and during each scheduled examination.

\section{Statistical Analysis}

Statistical analysis was performed using IBM SPSS Statistics for Windows, Version 22.0 (IBM Corp., Armonk, NY, USA) software. The distribution parameters were evaluated using the Shapiro-Wilks test and found to be in accordance with the parameters of normal distribution. Analysis of variance and Tukey's Honest Significant Difference test were used for inter-group comparisons. For intra-group comparison, a paired sample t-test was used. $\mathrm{P}<0.05$ was considered statistically significant.

\section{Results}

The mean preoperative foveal thickness in each group is provided in Table I. The mean foveal thickness of the DR group was significantly lower than that of the control group $(p=0.009)$. However, this small difference was not clinically significant. There were no statistically significant differences between other groups in preoperative mean macular thickness.

No statistically significant differences were observed between the groups in the first week after surgery. Differences 
Table I. Distribution of foveal thickness by group

\begin{tabular}{|c|c|c|c|c|}
\hline Foveal thickness & $\begin{array}{c}\text { Control group } \\
\text { Mean } \pm S D\end{array}$ & $\begin{array}{c}\text { No-DR group } \\
\text { Mean } \pm S D\end{array}$ & $\begin{array}{l}\text { NPDR group } \\
\text { Mean } \pm S D\end{array}$ & Ip \\
\hline Preoperative & $236.28 \pm|4.7|$ & $233.6 \pm 15.53$ & $227.56 \pm 8.42$ & $0.009 *$ \\
\hline \multicolumn{5}{|l|}{ Postoperative } \\
\hline I week & $239.4 \pm 15.19$ & $236.37 \pm 14.52$ & $238.53 \pm 13.57$ & 0.608 \\
\hline I month & $235.65 \pm 13.59$ & $237.49 \pm 14$ & $256.33 \pm 13.64$ & $0.00 I^{*}$ \\
\hline 6 months & $235.58 \pm 11.79$ & $233.49 \pm 13.86$ & $224.42 \pm 7.14$ & $0.00 I^{*}$ \\
\hline I year & $234.37 \pm 12.7$ & $231.77 \pm 11.06$ & $225.4 \pm 7.39$ & $0.00 I^{*}$ \\
\hline Preoperative I week2p & $0.001 *$ (increased) & $0.030 *$ (increased) & $0.001 *$ (increased) & \\
\hline Postoperativel month2p & 0.844 & $0.009 *$ (increased) & $0.001 *$ (increased) & \\
\hline One-way ANOVA Test & 2Paired-sample t-test & $*_{p}<0.05$ & & \\
\hline
\end{tabular}

ANOVA:Analysis of variance; No-DPR: No diabetic retinopathy; NPDR: Non-proliferative diabetic retinopathy.

in the mean central foveal thickness were observed between the groups at months I and $3(p=0.00 I)$. Binary comparisons were performed: the mean foveal thickness level of the NPDR group after I and 3 months was significantly higher than that of the control and the no-DR group $(p=0.00 \mathrm{I})$, and there were no statistically significant differences between the control and no-DR groups at months I and 3.

In the control group, a statistically significant increase was seen in the mean foveal thickness in the first week after surgery compared with the preoperative value $(p=0.00 \mathrm{I})$; however, no significant changes were observed in the first, third, and sixth months. The decline observed in the mean macular thickness in the first year, in comparison with the preoperative value, was statistically significant $(p=0.024)$.

In the no-DR group, in comparison with the mean pre- operative foveal thickness, there was a statistically significant increase in the first week $(p=0.030)$ and in the first month $(p=0.009)$, but no statistically significant differences were observed at the third and sixth months or the first year.

In a comparison with the mean preoperative foveal thickness in the DR group, there were statistically significant increases in the first week $(p=0.00 \mathrm{I})$ and the first $(p=0.00 \mathrm{I})$ and third months $(p=0.00 I)$. A statistically significant reduction was observed after 6 months $(p=0.002)$ and I year $(p=0.04 I)$.

The percent of change in foveal thickness by group over time from baseline can be seen in Table 2 .

A statistically significant difference in the mean foveal thickness was observed at week $I$ and months $I$ and 3 in comparison with the baseline $(p=0.00 \mathrm{I})$. Binary comparisons

Table 2. Percent change in foveal thickness by group at the first week; first, third, and sixth months; and first year postoperatively, in comparison with the mean preoperative foveal thickness

\begin{tabular}{|c|c|c|c|c|}
\hline $\begin{array}{l}\text { Foveal thickness } \\
\text { (\% change) }\end{array}$ & $\begin{array}{c}\text { Control group } \\
\text { Mean } \pm S D\end{array}$ & $\begin{array}{c}\text { No-DR group } \\
\text { Mean } \pm S D\end{array}$ & $\begin{array}{l}\text { NPDR group } \\
\text { Mean } \pm S D\end{array}$ & $\mathbf{p}$ \\
\hline I week & $1.33 \pm 1.92$ & $1.27 \pm 3.42$ & $4.83 \pm 4.63$ & $0.001 *$ \\
\hline I month & $0.12 \pm 8.4$ & $1.78 \pm 3.93$ & $12.76 \pm 6.83$ & $0.00 I^{*}$ \\
\hline 3 months & $0.67 \pm 4.65$ & $1.64 \pm 4.83$ & $|3.4| \pm 7.3$ & $0.001 *$ \\
\hline 6 months & $-0.2 \pm 2.67$ & $0.08 \pm 4.29$ & $-1.33 \pm 2.59$ & 0.112 \\
\hline I year & $-0.74 \pm 2.24$ & $-0.63 \pm 3.57$ & $-0.89 \pm 2.92$ & 0.914 \\
\hline \multicolumn{2}{|l|}{ One-way ANOVA test } & $*_{p}<0.05$ & & \\
\hline
\end{tabular}

ANOVA:Analysis of variance; No-DPR: No diabetic retinopathy; NPDR: Non-proliferative diabetic retinopathy. 
Table 3. Percent of patients by group with increased foveal thickness in the first week; first, third, and sixth months; and first year postoperatively

\begin{tabular}{lccccc} 
& $\begin{array}{c}\text { Ist } \\
\text { week }\end{array}$ & $\begin{array}{c}\text { Ist } \\
\text { month }\end{array}$ & $\begin{array}{c}\text { 3rd } \\
\text { month }\end{array}$ & $\begin{array}{c}\text { 6th } \\
\text { month }\end{array}$ & $\begin{array}{c}\text { Ist } \\
\text { year }\end{array}$ \\
\hline Control & $69.8 \%$ & $46.5 \%$ & $41.9 \%$ & $39.5 \%$ & $32.6 \%$ \\
No-DR & $65.1 \%$ & $55.8 \%$ & $67.4 \%$ & $34.9 \%$ & $32.6 \%$ \\
NPDR & $83.7 \%$ & $93 \%$ & $97.7 \%$ & $30.2 \%$ & $32.6 \%$ \\
\hline
\end{tabular}

No-DPR: No diabetic retinopathy; NPDR: Non-proliferative diabetic retinopathy.

were performed. The NPDR group had significantly higher macular thickness measurement results in the first week and at the first and third months than the control and no-DR groups $(p=0.00$ I).

No statistically significant differences were observed in the first week and first and third months after surgery between the control and no-DR groups.

There was no statistically significant difference between the groups at the sixth month and first year after surgery. When comparing group results 3 months after surgery, the percent increase in the DR group was significantly higher than those of the no-DR and control groups. Foveal thick- ness decreased 6 months after surgery.

Table 3 illustrates the percent of patients with increased postoperative foveal thickness. Values for the NPDR group in the first and third months were greater than those of the other groups; however, that difference was no longer observed at the sixth month and first year after surgery.

Figures $I$ and 2 show changes in foveal thickness over time and the percent of change in foveal thickness in the groups.

\section{Discussion}

Following phacoemulsification surgery, no visual impairment accompanied the subclinical thickening of the central macula, which could now be visualized using OCT and angiographic examination with fundus fluorescein (2I). The application of phacoemulsification can lead to inflammation due to the release of inflammatory substances directly involved in the thickening of macula, including prostaglandins (22). It has been reported that after phacoemulsification without complication, an inflammation response triggered by the surgery led to early edema in the macula $(23,24)$. Measurement of central macula thickness (CMT) at week I and months I and 3 indicated a significant change following phacoemulsification surgery that was without complication. The CMT later

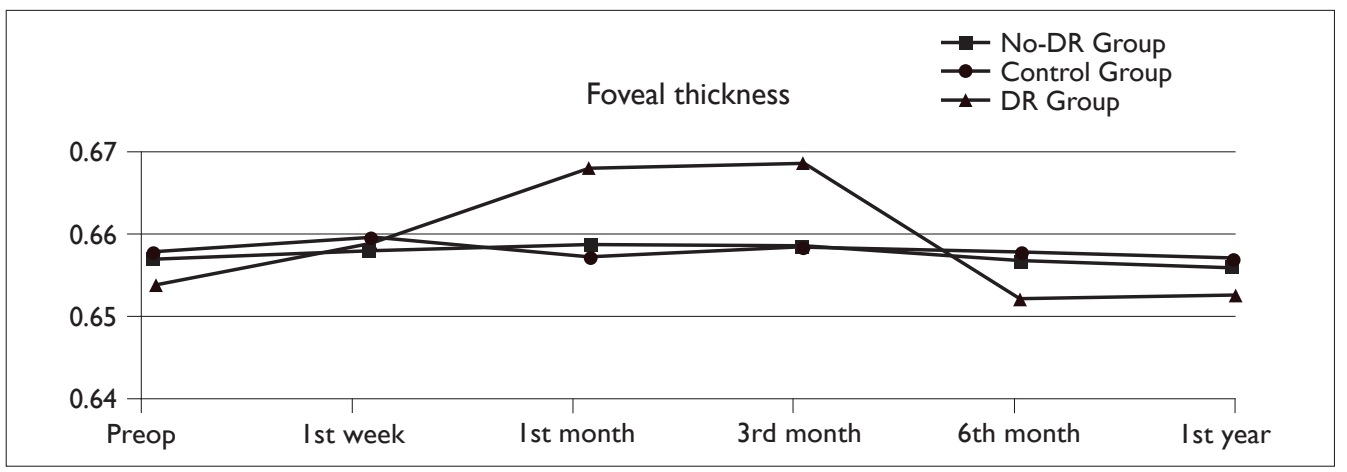

Figure I. Changes in foveal thickness over time.

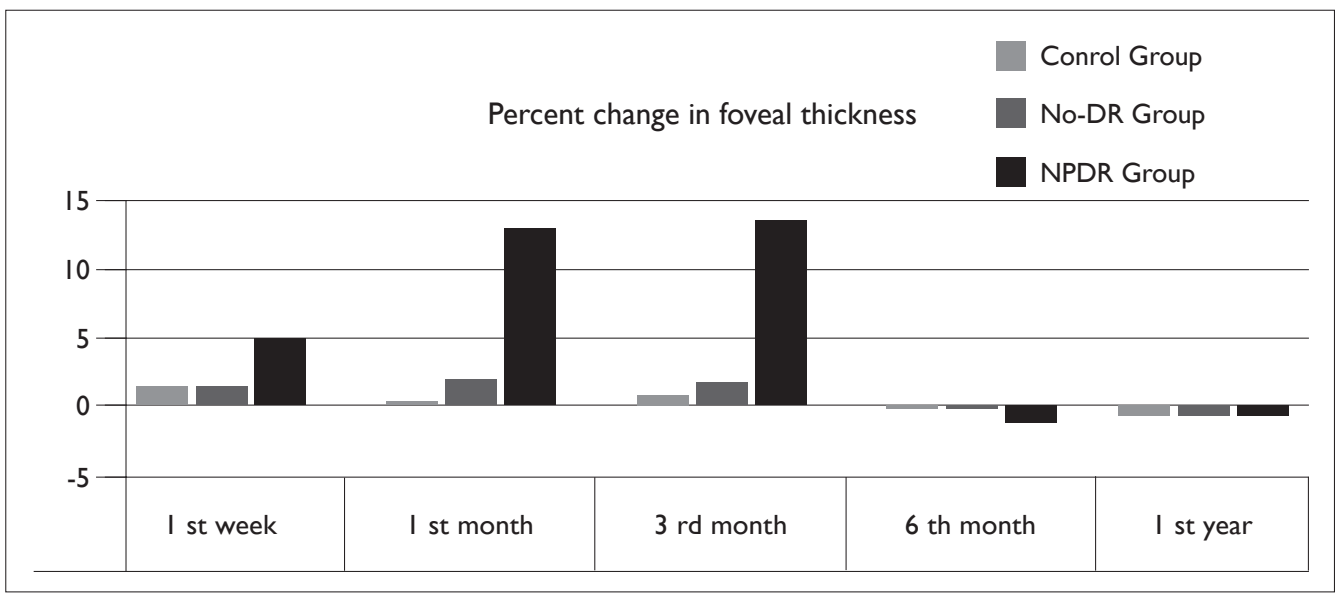

Figure 2. Percent change in foveal thickness by group. 
showed a gradual decrease in diabetes patients who also had concomitant mild NPDR. This indicates that compared with the control group and with diabetes patients with no DR, the phacoemulsification surgery had a stronger effect on the blood-aqueous barrier of diabetes patients with mild NPDR. Pseudophakic CME that develops following the surgical treatment of cataracts differs in many respects from diabetic edema of the macula, particularly in the immediate postoperative period. Pseudophakic CME is known to show regression within a period of $\mathrm{I}$ month (when associated with Irvine-Gass syndrome), while diabetic edema can exhibit progression for a period of more than 3 months (25). It is important for physicians to recognize the distinction between surgical treatment-related pseudophakic CME and diabetic edema of the macula.

Following cataract surgery, patients with diabetes are more likely to experience subclinical thickening or edema in the macula (26). Due largely to its ability to increase blood vessel permeability, VEGF assumes a central role in the development of diabetes-related microangiopathies (27). It is also known that proliferative DR patients have considerably higher VEGF levels in the vitreous humor (28). A number of risk factors are also involved in changing the extent of DR progression following phacoemulsification, such as the administration of insulin treatment to the patient, uncontrolled blood sugar level, and younger age. Some researchers have demonstrated that such factors had no impact on the degree of retinopathy progression $(29,30)$. In patients both with and without diabetes, CME following surgery is generally caused by prostaglandin-induced intraocular inflammation ( $3 \mathrm{I}$ ).

A comparison of the control group and diabetes patients without DR with patients with mild NPDR revealed that the NPDR group exhibited a statistically greater likelihood of macular thickening or edema in week I and in months I and 3 following phacoemulsification surgery.

In the present study, preoperative and postoperative CMT levels in diabetes patients without DR were compared with the level observed in the control group and in diabetes patients with mild NPDR. These comparisons indicated that, relative to the control group, phacoemulsification surgery (without complications) could potentially have a greater impact on the CMT value of diabetes patients than on the CMT value of the control group.

At month I following the surgery, it was observed that diabetes patients with mild NPDR exhibited significantly greater CMT values, while diabetes patients without DR demonstrated an almost significant rise in CMT values $(p=0.054)$. The greater CMT level might have been caused by the inflammatory response resulting from the phacoemulsification at I month after the surgery; however, it may equally have been associated with Irvine-Gass syndrome, which is induced by growth factors and cytokines (such as VEGF and prostaglandins) passing through the blood-aqueous barrier following phacoemulsification.

Certain researchers have suggested that in patients with a lengthy prior history of edema in the eye and maculopathy, the rapid rise in CMT level due to micro-injuries caused by the phacoemulsification surgery may result in a greater likelihood of postoperative CME $(32,33)$. The present study excluded patients with a history of severe proliferative or non-proliferative retinopathy, prior cataract surgery with complications, and prior CME. Such exclusion criteria can also be considered a limitation of the present study.

The present study revealed that, compared with the control group, diabetes patients without DR and with NPDR had a notably different CMT level I week and I and 3 months following phacoemulsification without complications. That is, a diabetes patient with mild NPDR had a greater CMT level at week $I$ and months $I$ and 3 after surgery. However, the CMT level began to gradually decrease starting from postoperative month 3 , and completely returning to a normal level by postoperative month 6 . Yet, it must also be noted that in all groups, any increase in CMT level was still subclinical. Neither the control group nor the diabetes patients without DR exhibited any statistically significantly greater CMT level in months 3 and 6 following surgery. The study findings revealed that phacoemulsification without complications had a minimal impact on the mechanisms and pathology of retinopathy in diabetes patients with mild NPDR - a group known to be associated with a greater occurrence of subclinical thickening in the macula following phacoemulsification relative to control groups and diabetes patients without retinopathy.

The present study demonstrated that in comparison with the control group and the no-DR group, phacoemulsification surgery without complications and accompanied by the implantation of an intraocular lens is associated with a significantly greater incidence of subclinical macular thickening in a mild NPDR group, specifically at week I and months I and 3 after surgery.

\section{Disclosures}

Peer-review: Externally peer-reviewed.

Conflict of Interest: None declared.

Authorship Contributions: Involved in design and conduct of the study (SA, YO); preparation and review of the study (SA, YO); data collection (SA); and statistical analysis (SA).

\section{References}

I. Song E, Sun H, Xu Y, Ma Y, Zhu H, Pan CW. Age-related cataract, cataract surgery and subsequent mortality: a systematic review and meta-analysis. PLoS One 20 I4;9:el I 2054. [CrossRef]

2. Klein BE, Klein R, Moss SE. Incidence of cataract surgery in the 
Wisconsin Epidemiologic Study of Diabetic Retinopathy. Am J Ophthalmol 1995; 1 19:295-300. [CrossRef]

3. Romero-Aroca P. Targeting the pathophysiology of diabetic macular edema. Diabetes Care 2010;33:2484-5. [CrossRef]

4. Chae JB, Joe SG, Yang SJ, Lee JY, Sung KR, Kim JY, et al. Effect of combined cataract surgery and ranibizumab injection in postoperative macular edema in nonproliferative diabetic retinopathy. Retina 2014;34:149-56. [CrossRef]

5. Krepler K, Biowski R, Schrey S, Jandrasits K, Wedrich A. Cataract surgery in patients with diabetic retinopathy: visual outcome, progression of diabetic retinopathy, and incidence of diabetic macular oedema. Graefes Arch Clin Exp Ophthalmol 2002;240:735-8. [CrossRef]

6. Dowler JG, Hykin PG, Lightman SL, Hamilton AM. Visual acuity following extracapsular cataract extraction in diabetes: a meta-analysis. Eye (Lond) 1995;9:3 13-7. [CrossRef]

7. Zaczek A, Olivestedt $G$, Zetterström $C$. Visual outcome after phacoemulsification and IOL implantation in diabetic patients. Br J Ophthalmol 1999;83:1036-4I. [CrossRef]

8. Chew EY, Benson WE, Remaley NA, Lindley AA, Burton TC, Csaky K, et al. Results after lens extraction in patients with diabetic retinopathy: early treatment diabetic retinopathy study report number 25. Arch Ophthalmol 1999;1 17:1600-6. [CrossRef]

9. Jaffe GJ, Burton TC, Kuhn E, Prescott A, Hartz A. Progression of nonproliferative diabetic retinopathy and visual outcome after extracapsular cataract extraction and intraocular lens implantation. Am J Ophthalmol 1992; I 4:448-56. [CrossRef]

10. Schatz H, Atienza D, McDonald HR, Johnson RN. Severe diabetic retinopathy after cataract surgery. Am J Ophthalmol 1994;1 17:3|4-21. [CrossRef]

II. Mittra RA, Borrillo JL, Dev S, Mieler WF, Koenig SB. Retinopathy progression and visual outcomes after phacoemulsification in patients with diabetes mellitus. Arch Ophthalmol 2000; 1 18:912-7.

12. Chung J, Kim MY, Kim HS, Yoo JS, Lee YC. Effect of cataract surgery on the progression of diabetic retinopathy. J Cataract Refract Surg 2002;28:626-30. [CrossRef]

13. Schrey S, Krepler K, Biowski R, Wedrich A. Midterm visual outcome and progression of diabetic retinopathy following cataract surgery. Midterm outcome of cataract surgery in diabetes. Ophthalmologica 2002;216:337-40. [CrossRef]

14. Romero-Aroca P, Fernández-Ballart J, Almena-Garcia M, Méndez-Marín I, Salvat-Serra M, Buil-Calvo JA. Nonproliferative diabetic retinopathy and macular edema progression after phacoemulsification: prospective study. J Cataract Refract Surg 2006;32:1438-44. [CrossRef]

15. Pollack A, Leiba H, Bukelman A, Abrahami S, Oliver M. The course of diabetic retinopathy following cataract surgery in eyes previously treated by laser photocoagulation. $\mathrm{Br} \mathrm{J} \mathrm{Oph-}$ thalmol 1992;76:228-31. [CrossRef]

16. Somaiya M, Burns JD, Mintz R, Warren RE, Uchida T, God- ley BF. Factors affecting visual outcomes after small-incision phacoemulsification in diabetic patients. J Cataract Refract Surg 2002;28: 1364-7I. [CrossRef]

17. Gass JD, Norton EW. Cystoid macular edema and papilledema following cataract extraction. A fluorescein fundoscopic and angiographic study. Arch Ophthalmol 1966;76:646-61. [CrossRef]

18. Schepens CL, Avila MP, Jalkh AE, Trempe CL. Role of the vitreous in cystoid macular edema. Surv Ophthalmol 1984;28 Suppl:499-504. [CrossRef]

19. Henricsson M, Heijl A, Janzon L. Diabetic retinopathy before and after cataract surgery. Br J Ophthalmol 1996;80:789-93.

20. Kim SJ, Equi R, Bressler NM. Analysis of macular edema after cataract surgery in patients with diabetes using optical coherence tomography. Ophthalmology 2007; I 44:88I-9. [CrossRef]

21. Lima-Gómez V, Razo Blanco-Hernández DM. Expected value of foveal thickness in macular edema in Mexican patients with diabetes. Cir Cir 2012;80:109-14.

22. Chen D, Zhu J, Li J, Ding XX, Lu F, Zhao YE. Effect of simulated dynamic intraocular pressure on retinal thickness measured by optical coherence tomography after cataract surgery. Int J Ophthalmol 2012;5:687-93.

23. Miyanaga M, Miyai T, Nejima R, Maruyama Y, Miyata K, Kato S. Effect of bromfenac ophthalmic solution on ocular inflammation following cataract surgery. Acta Ophthalmol 2009;87:300 5. [CrossRef]

24. Bannale SG, Pundarikaksha HP, Sowbhagya HN. A Prospective, Open-label Study to Compare the Efficacy and the Safety of Topical Loteprednol Etabonate and Topical Flurbiprofen Sodium in Patients with Post-Operative Inflammation after Cataract Extraction. J Clin Diagn Res 2012;6: 1499-503. [CrossRef]

25. Schmier JK, Halpern MT, Covert DW, Matthews GP. Evaluation of costs for cystoid macular edema among patients after cataract surgery. Retina 2007;27:62I-8. [CrossRef]

26. Oh JH, Chuck RS, Do JR, Park CY. Vitreous hyper-reflective dots in optical coherence tomography and cystoid macular edema after uneventful phacoemulsification surgery. PLoS One 20। 4;9:e95066. [CrossRef]

27. Kuiper EJ, Van Nieuwenhoven FA, de Smet MD, van Meurs JC, Tanck MW, Oliver N, et al. The angio-fibrotic switch of VEGF and CTGF in proliferative diabetic retinopathy. PLoS One 2008;3:e2675. [CrossRef]

28. Abu El-Asrar AM, Mohammad G, Nawaz MI, Siddiquei MM, Van den Eynde $K$, Mousa $A$, et al. Relationship between vitreous levels of matrix metalloproteinases and vascular endothelial growth factor in proliferative diabetic retinopathy. PLoS One 20|3;8(I2):e85857. [CrossRef]

29. Nascimento MA, Lira RP, Kara-José N, Arieta CE. Predictive value of preoperative fasting glucose test of diabetic patients regarding surgical outcome in cataract surgery. Arq Bras Oftalmol 2005;68:213-7. [CrossRef]

30. Suto C, Hori S, Kato S, Muraoka K, Kitano S. Effect of periop- 
erative glycemic control in progression of diabetic retinopathy and maculopathy. Arch Ophthalmol 2006; 124:38-45. [CrossRef]

3 I. Simó R, Sundstrom JM, Antonetti DA. Ocular Anti-VEGF therapy for diabetic retinopathy: the role of VEGF in the pathogenesis of diabetic retinopathy. Diabetes Care 20I4;37:893-9.

32. Hartnett ME, Tinkham N, Paynter L, Geisen P, Rosenberg P, Koch $\mathrm{G}$, et al. Aqueous vascular endothelial growth factor as a predictor of macular thickening following cataract surgery in patients with diabetes mellitus. Am J Ophthalmol 2009;|48:89590I.el. [CrossRef]

33. Lanzagorta-Aresti A, Palacios-Pozo E, Menezo Rozalen JL, Navea-Tejerina A. Prevention of vision loss after cataract surgery in diabetic macular edema with intravitreal bevacizumab: a pilot study. Retina 2009;29:530-5. [CrossRef] 